\title{
LEPR c.668A $>G$ polymorphism in a cohort of Sri Lankan women with pre-eclampsia / pregnancy induced hypertension: a case control study
}

Kamani Hemamala Tennekoon ${ }^{1 *}$, Wijesekara Liyanage Indika ${ }^{1}$, Rohan Sugathadasa ${ }^{1}$, Eric Hamilton Karunanayake ${ }^{1}$, Jayalath Kumarasiri ${ }^{2}$ and Ajita Wijesundera ${ }^{2}$

\begin{abstract}
Background: Leptin is known to be elevated in pre-eclampsia/ pregnancy induced hypertension (PE/PIH). However the reports on the association of leptin receptor (LEPR) c.668A>G polymorphism with PE/PIH are inconsistent.

Findings: $\angle E P R$ c.668A $>G$ polymorphism was studied in a cohort of women with PE/PIH $(N=61)$ and normotensive pregnancies $(N=40)$ by polymerase chain reaction / restriction fragment length polymorphism. Genotype and allele frequencies were in Hardy-Weinberg equilibrium within both groups (Chi square test). Allele and genotype frequencies were not significantly different between PE/PIH and normotensive pregnancies (Chi square test). Leptin levels (Kruskal Wallis analysis of variance) and leptin/body mass index (one way analysis of variance) were not significantly different between genotypes within each group. However, leptin (Mann Whitney $U$ test) and leptin normalised to body mass index (unpaired t test) were significantly higher in PE/PIH women homozygous and heterozygous for the G668 allele than in respective normotensives.

Conclusions: Whether the leptin receptor c.668A>G polymorphism increases the risk of developing PE/PIH in Sri Lankan women remains inconclusive in view of the smaller sample studied. However leptin levels in PE/PIH appeared to be modulated by this polymorphism.
\end{abstract}

Keywords: Leptin, Leptin receptor polymorphism, Pregnancy induced hypertension, Pre-eclampsia

\section{Findings}

\section{Background}

Leptin, the first adipocyte hormone identified brings about biological effects via its cognate receptor [1]. Leptin receptor (LEPR) exists in several isoforms [2]. The full length isoform as well as some isoforms with short cytoplasmic domains are implicated in signal transduction [3-5]. LEPR isoform without the cytoplasmic and transmembrane domains is shed from the cells and circulates as the soluble leptin receptor. This modulates biological availability of leptin [6]. Several single nucleotide polymorphisms (SNPs) have also been identified in LEPR [7]. Of the SNPs reported, c.668A $>G$ polymorphism in exon 6 (rs 1137101) has been reported to be

\footnotetext{
* Correspondence: kamani@ibmbb.cmb.ac.lk

${ }^{1}$ Institute of Biochemistry, Molecular Biology and Biotechnology, University of Colombo, No: 90, Cumaratunga Munidasa Mawatha, Colombo 3, Sri Lanka Full list of author information is available at the end of the article
}

associated with body mass index, breast cancer and age at menarche etc [8-10].

Pre-eclampsia / pregnancy induced hypertension (PE/ $\mathrm{PIH})$ is a pregnancy complication with increased fetal and maternal morbidity and mortality. It is thought to arise due to abnormal placentation followed by a maternal systemic disorder. Several studies including ours have shown that PE/PIH is associated with elevated circulating leptin levels and reduced levels of soluble leptin receptor compared to normotensive pregnancies [11-14]. We previously demonstrated that a polymorphism in the leptin gene increases risk of PE/PIH [14]. Studies on the association of $L E P R$ c.668A $>G$ polymorphism with $\mathrm{PE} /$ $\mathrm{PIH}$ are limited and findings have been inconsistent $[15,16]$. There are no data on the possible association of this polymorphism with PE/PIH for Sri Lanka or for any other South Asian population to the best of our knowledge. Thus we examined the possible association of

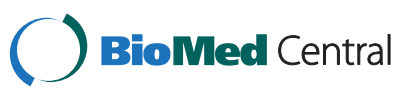


LEPR c. $668 \mathrm{~A}>\mathrm{G}$ polymorphism in a cohort of Sri Lankan women with $\mathrm{PE} / \mathrm{PIH}$.

\section{Results and discussion}

There were $33 \mathrm{PE}$ and $28 \mathrm{PIH}$ patients in the PE/PIH group. Genotype and allele distribution was not significantly different between PE and PIH (Chi square test, $\mathrm{P}=0.969 ; \mathrm{P}=0.964$ respectively). Therefore both $\mathrm{PE}$ and $\mathrm{PIH}$ patients were analysed together. Both the PE/PIH and control group were predominantly Sinhalese with only 4 patients in the PE/PIH group and one subject in the control group belonging to other ethnic groups (ie: PE/PIH: 3 Muslims, 1 Tamil; control: 1 Muslim). Thus ethnicity was not taken into account in the analysis.

Genotype and allele distributions in $\mathrm{PE} / \mathrm{PIH}$ and normal pregnancy are shown in Table 1 . Heterozygosity for the $L E P R$ c.668A $>G$ polymorphism was the most common genotype in both groups. Genotype distributions were in Hardy-Weinberg equilibrium within PE/PIH $(\mathrm{P}=0.752)$ and normotensive pregnancy $(\mathrm{P}=0.710)$ groups. Furthermore genotype frequencies did not significantly differ between the two groups $(P=0.311)$. Though the $A 668$ allele was more frequent in $\mathrm{PE} / \mathrm{PIH}$ than in normal pregnancy, the difference was not statistically significant (Chi square test: $\mathrm{P}=0.372$ ) and the A668 allele did not confer a significantly higher risk of developing PE/PIH [relative risk (95\% confidence limits) $1.126(0.899$ to 1.408$)]$.

Leptin levels and leptin normalized to body mass index of PE/PIH subjects included in the present study and some of the controls have been presented elsewhere and we reported that both the leptin levels and leptin normalized to body mass index were significantly higher in PE/PIH [14]. Reanalysis by LEPR c.668A>G genotype did not show any significant effect of the genotype on leptin levels or leptin normalized to body mass index (Table 2) within either group, though there was a tendency for levels to increase from AA genotype to GG genotype within the PE/PIH group. Leptin and leptin normalized to body mass index remained significantly

Table 1 Genotype and allele frequencies in pre-eclampsia / pregnancy induced hypertension (PE/PIH) and normal pregnancy

\begin{tabular}{lccc}
\hline \multicolumn{4}{c}{ PE/PIH: N (\%) Normal pregnancy: N (\%) P value } \\
\hline Genotype & & & \\
A668 homozygous & $11(18 \%)$ & $06(15 \%)$ & \\
A668G heterozygous & $42(69 \%)$ & $10(25 \%)$ & \\
G668 homozygous & $08(13 \%)$ & & \\
Allele & & $36(45 \%)$ & \\
A668 & $64(52 \%)$ & $44(55 \%)$ & $P=0.371$ \\
G668 & $58(48 \%)$ &
\end{tabular}

$\mathrm{P}$ values are for the Chi square test comparing $\mathrm{PE} / \mathrm{PIH}$ and normal pregnancy. higher in $\mathrm{PE} / \mathrm{PIH}$ women who were heterozygous ( $\mathrm{p}=0.0007, \mathrm{p}=0.0026$ respectively) and homozygous for the $G 668$ allele ( $\mathrm{p}=0.0085, \mathrm{p}=0.0189$ respectively) than in the respective controls, but were not significantly different between PE/PIH and controls homozygous for the A668 allele. Furthermore, BMI was significantly higher in heterozygotes $(\mathrm{p}=0.0093)$ in the $\mathrm{PE} / \mathrm{PIH}$ group compared to respective controls. BMI was higher in the G668 homozygotes $(\mathrm{p}=0.0616)$ in the $\mathrm{PE} / \mathrm{PIH}$ group, but this did not achieve a statistical significance.

Association of leptin and polymorphisms of the leptin gene with increased risk of PE/PIH has been already well documented [12-14]. However, there are only a very few reports on the association of $L E P R \quad$ c.668 $A>G$ polymorphism with $\mathrm{PE} / \mathrm{PIH}$ and these have remained inconsistent. A study from Hungary showed that the A668 allele was significantly associated with severe PE [15] while no such association was observed in the HELLP syndrome [17], perhaps signifying differences in the underlying pathology. A recent study from Germany did not find an association of $L E P R$ c.668A $>G$ polymorphism with either PE or HELLP syndrome [16].

We previously demonstrated significantly higher plasma leptin levels and free leptin index (leptin levels/ soluble leptin receptor levels) in women with $\mathrm{PE} / \mathrm{PIH}$ [14]. An increased risk of the disease was also conferred by the $A$ allele of $-2548 \mathrm{G} / A$ polymorphism of the leptin gene. In the present study $L E P R \quad c .668 A>G$ polymorphism of the same women with PE/PIH was studied. However, the prevalence of $\mathrm{A}$ and $\mathrm{G}$ alleles as well as different genotypes was not significantly different between PE/PIH and normotensive pregnancies. Thus our results contrast with those of Rigo et al [15], but support recent findings of Wiedemann et al [16].

Some investigators have shown that G668 homozygosity is associated with significantly higher levels of leptin when compared to $A 668$ homozygosity $[18,19]$. In a recent study on a multiethnic cohort comprising of African, AfricanAmerican, African-Caribbean, Caucasian and Asian/other ethnic groups this effect was observed only in Caucasians [20]. In the present study leptin levels and leptin normalized to BMI appeared to increase from $A 668$ homozygosity to $G 668$ homozygosity with heterozygotes having intermediate levels in PE/PIH. The differences did not reach a statistical significance presumably due to the smaller numbers in wild type and mutant homozygous groups. Such an effect was not seen among the controls.

LEPR has two cytokine receptor homology domains known as CRH1 and CRH2. c.668A $>G$ polymorphism is located in the CRH1 domain. It has been suggested that $\mathrm{CRH} 2$ domain is adequate for signal transduction via LEPR. When the functional significance of this polymorphism was studied using a mouse model it did not show an effect on leptin signaling [21]. Our inability to 
Table 2 Leptin levels (geometric mean and 95\% confidence levels) and leptin normalized to body mass index (mean + SD) in pre-eclampsia/ pregnancy induced hypertension (PE/PIH) and normal pregnancy by genotype

\begin{tabular}{lllllr}
\hline Genotype & $\begin{array}{l}\text { PE/PIH } \\
\text { Leptin } \mathbf{n g} / \mathbf{m L}\end{array}$ & $\begin{array}{l}\text { Normal pregnancy } \\
\text { Leptin } \mathbf{n g} / \mathbf{m L}\end{array}$ & $\mathbf{P}$ value & $\begin{array}{l}\mathrm{PE} / \mathrm{PIH} \\
\text { Leptin/BMI }\end{array}$ & $\begin{array}{l}\text { Normal pregnancy } \\
\text { Leptin/BMI }\end{array}$ \\
\hline A668 & 56.47 & 43.04 & $\mathrm{P}=0.1193$ & $2.265 \pm 0.797$ & $1.668 \pm 0.155$ \\
homozygous & $(43.55,73.21)$ & $(34.91,53.05)$ & & & $P=0.0934$ \\
A668G & 62.51 & 42.41 & $\mathrm{P}=0.0007$ & $2.334 \pm 0.772$ & $1.775 \pm 0.527$ \\
heterozygous & $(56.48,69.19)$ & $(34.79,51.69)$ & & & $\mathbf{P}=0.0026$ \\
G668 & 73.56 & 45.29 & $\mathrm{P}=0.0085$ & $2.553 \pm 0.857$ & $1.764 \pm 0.384$ \\
homozygous & $(58.45,92.57)$ & $(35.27,58.17)$ & & & $P=0.0189$
\end{tabular}

$\mathrm{P}$ values are for Mann Whitney $\mathrm{U}$ test comparing $\mathrm{PE} / \mathrm{PIH}$ with normal pregnancy.

observe an association of LEPR $c .668 A>G$ polymorphism with $\mathrm{PE} / \mathrm{PIH}$ in the present study may have resulted from this lack of an effect on leptin signaling.

Increased maternal leptin in pregnancy is contributed both from the placenta and the adipose tissue. Following the delivery, maternal leptin levels return to prepregnancy levels confirming that the placenta is the major source of maternal leptin during pregnancy [22$24]$. Even when accounted for adipose tissue contribution by normalizing leptin levels to BMI, genotype associated effect remained within the $\mathrm{PE} / \mathrm{PIH}$ group indicating that the LEPR $c .668 A>G$ polymorphism is likely to modulate leptin levels in PE/PIH. A larger cohort of patients needs to be studied to confirm or refute this finding as well as to examine the effect of $L E P R$ c.668A $>G$ on the risk of PE/PIH in Sri Lankan women as the present study is underpowered in view of the smaller number of subjects studied.

\section{Conclusions}

Whether the leptin receptor c.668A $>G$ polymorphism increases the risk of developing PE/PIH in Sri Lankan women thus remains inconclusive due to the limited power of the present study. The effect of leptin receptor c.668A $>G$ polymorphism on the risk of developing PE/ $\mathrm{PIH}$ and whether $L E P R \quad$ c.668A $>G$ polymorphism is likely to significantly modulate leptin levels in PE/PIH need to be studied using a larger cohort of patients.

\section{Methods}

\section{Subjects}

Sixty one women with PE/PIH were selected from those who participated in a previous study on the association of leptin with $\mathrm{PE} / \mathrm{PIH}$. Their characteristics have been described in detail elsewhere [14]. Forty women with normotensive pregnancies were included as controls. Of these 19 subjects were selected from the control subjects from our previous study on the basis of availability of DNA aliquots. Remaining 21 subjects were recruited from the same tertiary care hospital according to the previously used study protocol. A sample size of 40 subjects in each group has a $90 \%$ power at a significance level of 0.05 to detect a 0.35 increase in the prevalence of G668 allele in the test group assuming a prevalence 0.3 for the control group. Ethical approval from the Research, Ethics and Higher Degrees Committee of the Institute of Biochemistry, Molecular Biology and Biotechnology and written informed consent from the study participants were obtained prior to the study. Women in both groups had naturally conceived singleton pregnancies. Exclusion criteria were diabetes mellitus, gestational diabetes, chronic hypertension, renal disease, polycystic ovarian syndrome, menstrual cycle disturbances, previous history of infertility, as well as family history of diabetes mellitus or chronic hypertension.

On admission to the study, maternal age, height, weight and blood pressure were recorded and a sample of urine tested for proteinuria. Criteria for diagnosing PE/PIH have been described before [14]. Persistent (6 or more hours apart) blood pressure of at least $140 / 90 \mathrm{mmHg}$ arising after 20 weeks of gestation was considered as PIH. Urine protein concentration $>300 \mathrm{mg} / \mathrm{l}$ or more (or $1+$ on a urine dipstick) in addition to hypertension was considered as pre-eclampsia. A peripheral venous blood sample was collected on diagnosis and before commencement of any treatment from the PE/PIH patients and on admission to the study in the third trimester from the controls.

Genomic DNA extracted from peripheral blood leukocytes was used for amplification by polymerase chain reaction (PCR) using exon specific primers. PCR products were digested with Msp1 enzyme for restriction fragment length polymorphism analysis by Agarose gel electrophoresis [7].

Polymorphism at nucleotide position 668 from $\mathrm{A}>\mathrm{G}$ changes codon 223 from CAG [coding for glutamine (Q)] to CGG [coding for Arginine (R)]. This change results in an Msp 1 restriction site that cleaves the PCR product on exposure to the enzyme. Gels were manually scored as presence ( $G 668$ homozygosity), absence ( $A 668$ homozygosity) and heterozygosity of polymorphism. RFLP results were further confirmed by repeat analysis and by direct sequencing of representative samples. Chi- 
square test was used to ascertain whether the genotype and allele distributions were in Hardy-Weinberg equilibrium within each group, as well as to test whether the allele or genotype distributions differed between $\mathrm{PE} / \mathrm{PIH}$ and normotensive pregnancies.

Leptin levels and leptin normalized to body mass index were compared between genotypes within each group using Kruskall Wallis ANOVA and one way ANOVA respectively. Leptin levels and leptin normalized to body mass index between $\mathrm{PE} / \mathrm{PIH}$ and controls were compared after stratifying data by genotype using Mann Whitney $U$ test and unpaired Student's t test respectively.

\section{Competing interests}

Authors declare that they have no competing interests.

\section{Acknowledgements}

We thank Director and staff of Castle Street Hospital for Women, Colombo for giving access to patients and Sida Secretariat for Research Cooperation Grant for Molecular Biology and Biotechnology for funding. This work constituted part of the MSC studies of WLI.

\section{Author details}

'Institute of Biochemistry, Molecular Biology and Biotechnology, University of Colombo, No: 90, Cumaratunga Munidasa Mawatha, Colombo 3, Sri Lanka.

${ }^{2}$ Castle Street Hospital for Women, Colombo 8, Sri Lanka.

\section{Authors' contributions}

KHT designed the study, analysed data and wrote the draft, WLI carried out genotyping and analysed data, RS collected samples and carried out leptin assays, EHK designed the study, JK and AW carried out clinical assessment of the subjects, all authors approved the final version of the paper.

Received: 9 February 2012 Accepted: 19 June 2012

Published: 19 June 2012

\section{References}

1. Tartaglia LA: Leptin receptor. J Biol Chem 1997, 272:6093-6096.

2. Fei H, Okano HJ, Li C, Lee G-W, Zhao C, Darnell R, Friedman M: Anatomic localization of alternatively spliced leptin receptors (Ob-R) in the mouse brain and other tissues. PNAS 1997, 94:7001-7005.

3. Murakami T, Yamashita T, Lida M, Kuwajima M, Shima K: A short form of leptin receptor performs signal transduction. Biochem Biophys Res Commun 1997, 231:26-29.

4. Bates SH, Stearns WH, Dundon TA, Schubert M, Tso AW, Wang Y, Banks AS, Lavery HJ, Haq AK, Maratos-Flier E, Neel BG, Schwartz MW, Myers MG Jr: STAT3 signalling is required for leptin regulation of energy balance but not reproduction. Nature 2003, 421:856-859

5. Cauzac M, Czuba D, Girard J, Hauguel-de Mouzon S: Transduction of leptin growth signals in placental cells is independent of JAK-STAT activation. Placenta 2003, 24:378-384.

6. Huang L, Wang Z, Li C: Modulation of circulating leptin levels by its soluble receptor. J Biol Chem 2001, 276:6343-6634.

7. Matsuoka N, Ogawa Y, Hosoda K, Matsuda J, Masuzaki H, Miyawaki T, Azuma N, Natsui K, Nishimura H, Yoshimasa Y, Nishi S, Thompson DB, Nakao K: Human leptin receptor gene in obese Japanese subjects: evidence against either obesity-causing mutations or association of sequence variants with obesity. Diabetologia 1997, 40:1204-1210.

8. Quinton ND, Lee AJ, Ross RJ, Eastell R, Blakemore Al: A single nucleotide polymorphism (SNP) in the leptin receptor is associated with BMI, fat mass and leptin levels in postmenopausal Caucasian women. Hum Genet 2001, 108:233-236.

9. Snoussi K, Strosberg AD, Noureddine B, Slim BA, Noureddine AH, Lotfi C: Leptin and leptin receptor polymorphisms are associated with increased risk and poor prognosis of breast carcinoma. BMC Cancer 2006, 6:38.
10. Riestra P, Garcia-Anguita A, Torres-Cantero A, Bayonas MJ, de Oya M, Garces C: Association of the $\mathrm{C} .668 \mathrm{~A}>\mathrm{G}$ polymorphism with age at menarche in the leptin receptor gene in humans. Biol Reprod 2011, 84:752-755.

11. McCarthy JF, Misra DN, Roberts JM: Maternal plasma leptin level is increased in preeclampsia and positively correlates with fetal cord concentration. Am J Obstet Gynecol 1999, 180:731-736.

12. Muy-rivera M, Ning Y, Frederick IO, Vadachkoria S, Luthy DA, Williams MA: Leptin, soluble leptin and leptin gene polymorphism in relation to preeclampsia. Physiol Res 2005, 54:167-174.

13. Laivuori H, Gallaher MJ, Collura L, Crombleholme WR, Markovic N, Rajakumar A Hubel CA, Roberts JM, Powers RW: Relationships between maternal plasma leptin, placental leptin mRNA and protein in normal pregnancy, preeclampsia and intrauterine growth restriction without preeclampsia. Mol Hum Reprod 2006, 12:551-556.

14. Sugathadasa BHKR, Tennekoon KH, Karunanayake EH, Kumarasiri JM, Wijesundere APDeS: Association of $-2548 \mathrm{G} / \mathrm{A}$ polymorphism in the leptin gene with preeclampsia/ pregnancy induced hypertension. Hypertens Pregnancy 2010, 29:366-374.

15. Rigo J, Szendei G, Rosta K, Fekete A, Bogi K, Molvarec A, Ronai Z, Ver A: Leptin receptor gene polymorphisms in severely pre-eclamptic women. Gynecol Endocrinol 2006, 22:521-525.

16. Wiedemann A, Vocke F, Fitzgerald JS, Markert UR, Jeschke U, Lohse P, Toth B: Leptin gene (TTTC)(n) microsatellite polymorphism as well as leptin receptor $\mathrm{R} 223 \mathrm{Q}$ and PPARgamma2 P12A substitutions are not associated with hypertensive disorders in pregnancy. Am J Reprod Immunol 2010, 63:310-317.

17. Varkonyi T, Lazar L, Molvarec A, Than NG, Rigo J Jr, Nagy B: Leptin receptor (LEPR) SNP polymorphisms in HELLP syndrome patients determined by quantitative real-time PCR and melting curve analysis. BMC Med Genet 2010, 11:25

18. Yiannakouris N, Yannakoulia M, Melistas L, Chan JL, Klimis-Zacas D, Mantzoros CS: The C.668A $>\mathrm{G}$ polymorphism of the leptin receptor gene is significantly associated with obesity and predicts a small percentage of body weight and body composition variability. J Clin Endocrinol Metab 2001, 86:4434-4439.

19. Murugesan D, Arunachalam T, Ramamurthy $V$, Subramanian S: Association of polymorphisms in leptin receptor gene with obesity and type 2 diabetes in the local population of Coimbatore. Indian J Hum Genet 2010, 16:72-77.

20. Ragin CC, Dallal C, Okobia M, Modugno F, Chen J, Garte S, Taioli E: Leptin levels and leptin receptor polymorphism frequency in healthy populations. Infect Agent Cancer 2009, 4(Suppl 1):S13.

21. Stratigopoulos G, LeDuc CA, Matsuoka N, Gutman R, Rausch R, Robertson SA, Myers MG Jr, Chung WK, Chua SC Jr, Leibel RL: Functional consequences of the human leptin receptor (LEPR) C.668A $>G$ transversion. Obesity 2009, 17:126-135.

22. Senaris R, Garcia-Cabbalaero T, Casabiell X, Gallegeo R, Castro R, Considine RV, Dieguez, Casanueva FF: Synthesis of leptin in human placenta. Endocrinology 1997, 138:4501-4504

23. Sivan E, Whittaker PG, Sinha D, Homko CJ, Lin M, Reece EA, Boden G: Leptin in human pregnancy: the relationship with gestational hormones. Am J Obstet Gynecol 1998, 17:1128-1132.

24. Leperca J, Challier JC, Guerre-Millo M, Cauzac M, Vidal H, Hauguel-de Mouzon S: Prenatal leptin production: evidence that fetal adipose tissue produces leptin. J Clin Endocrinol Metab 2001, 86:2409-2413.

doi:10.1186/1756-0500-5-308

Cite this article as: Tennekoon et al:: $L E P R$ c.668A $>G$ polymorphism in a cohort of Sri Lankan women with pre-eclampsia / pregnancy induced hypertension: a case control study. BMC Research Notes 2012 5:308. 